\title{
A NEW SPECIES OF ANT BELONGING TO THE PHEIDOLE PILIFERA COMPLEX (HYMENOPTERA : FORMICIDAE)
}

\author{
By ROBERT E. GREGG \\ Department of Biology, University of Colorado
}

A small collection of ants representing the genus Pheidole from several localities in Western United States was given to me recently by Dr. W. S. Creighton. Among these specimens are samples of several colonies from Oregon which prove to be a new species. The description of this ant follows herewith.

Pheidole creightoni sp. nov.

Soldier: Length, $3.75 \mathrm{~mm}$; head index, 0.94; head length, $1.33 \mathrm{~mm}$.; thorax length, $1.00 \mathrm{~mm}$.

Head subquadrate, slightly longer than broad, with prominent occipital corners and a deep occipital emargination leading to a pronounced cephalic sulcus. In profile, the occipital border is flat and slopes forward, but joins the vertex in a rounded though noticeable angle rather than through a continuous curve. Anterior clypeal border broadly emarginate in the center, the lateral borders nearly straight. Frontal carinae flat and slightly divergent. Frontal area well-defined and in the shape of an isosceles triangle. Eyes lateral and placed distinctly anterior to the middle of the head. Antennae 12-segmented, with a club composed of the last three articles; funicular segments 5 to 8, slightly longer than broad; antennal scape distinctly bent at the base, with only a faint indication of flattening, and with its distal portion definitely wider than the basal portion. The scape extends posteriorly a little less than one-half the distance from its insertion to the occipital corner of the head. Mandibles heavy, abruptly convex, and provided with two very blunt teeth at the apex; remainder of the cutting border entire.

Thorax convex, with well-marked humeral angles; promesonotum does not descend before reaching the 
mesoëpinotal suture; suture deep but narrow; epinotal spines projecting upward and outward, blunt, about onehalf as long as the distance separating their bases. Petiolar peduncle long, node narrow in the antero-posterior direction and shallowly emarginate on the crest. Postpetiole twice as wide as the petiole, lenticular in shape from above as a result of pronounced lateral conules which are convex anteriorly and concave posteriorly.

Abdomen elliptical and somewhat depressed; of the shape usually characteristic for the genus.

Sculpture: Pronounced transverse rugae on the occiput, extending into and across the cephalic furrow, but fading out on the vertex; finer, longitudinal rugae on the frons, anterior surfaces of the genae, and on the clypeus; interrugal striations and granules very fine, so that the sculptured areas of the head are shining; non-sculptured regions (vertex, gula, and frontal area) are exceedingly smooth and shining; mandibles striate and shining. Thorax glabrous and shining except the granular mesopleurae and epinotal pleurae; basal face of the epinotum between the spines for the most part smooth; mesoëpinotal suture cross-striate. Petiole and postpetiole finely granular, almost smooth. Gaster smooth and shining.

Pilosity: Head, thorax, petiole, postpetiole, gaster, legs, funiculi, and scapes covered with long, finely pointed hairs of varying length.

Color: Head yellowish red, mandibles brown, thorax brownish red, gaster dark brown, legs and antennae light brown.

Worker: Length, $2.08 \mathrm{~mm}$.; head index, 0.86 ; head length, $0.58 \mathrm{~mm}$.; thorax length, $0.67 \mathrm{~mm}$.

Head subquadrate, occipital border slightly emarginate. Genae striate between eyes and mandibular insertions, otherwise smooth and shining. Thorax smooth and shining except mesopleurae and the dorsum and sides of the epinotum which are granular; interspinal space and declivity smooth. Petiole and postpetiole shagreened. Epinotal

Explanation of Plate 2

Pheidole creightoni, a. soldier; b. head of soldier; c. worker. All figures are drawn to the same scale. 

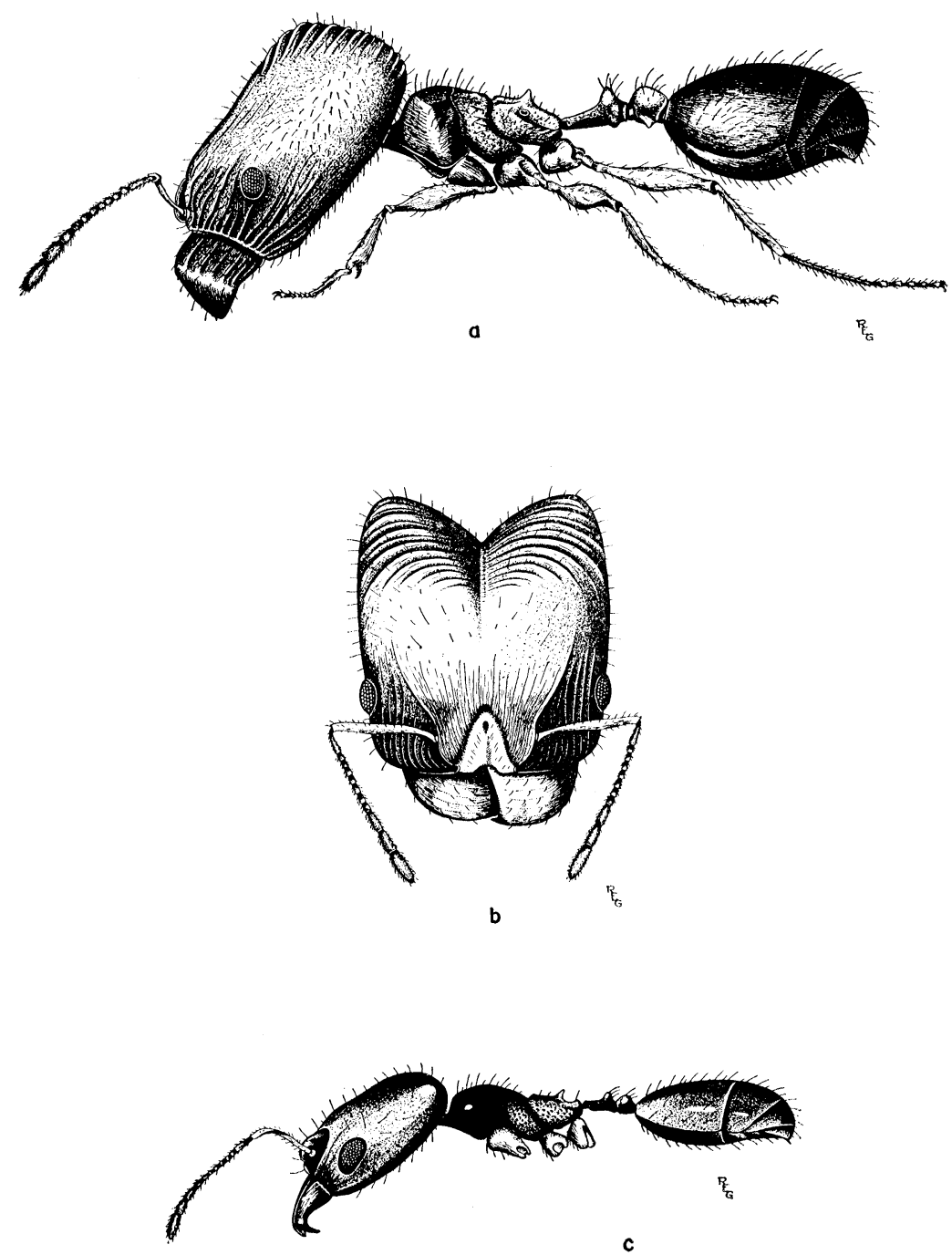

GregG - Pheidole Creightoni 


\section{TABLE I - SOLDIERS (MAJOR WORKERS)}

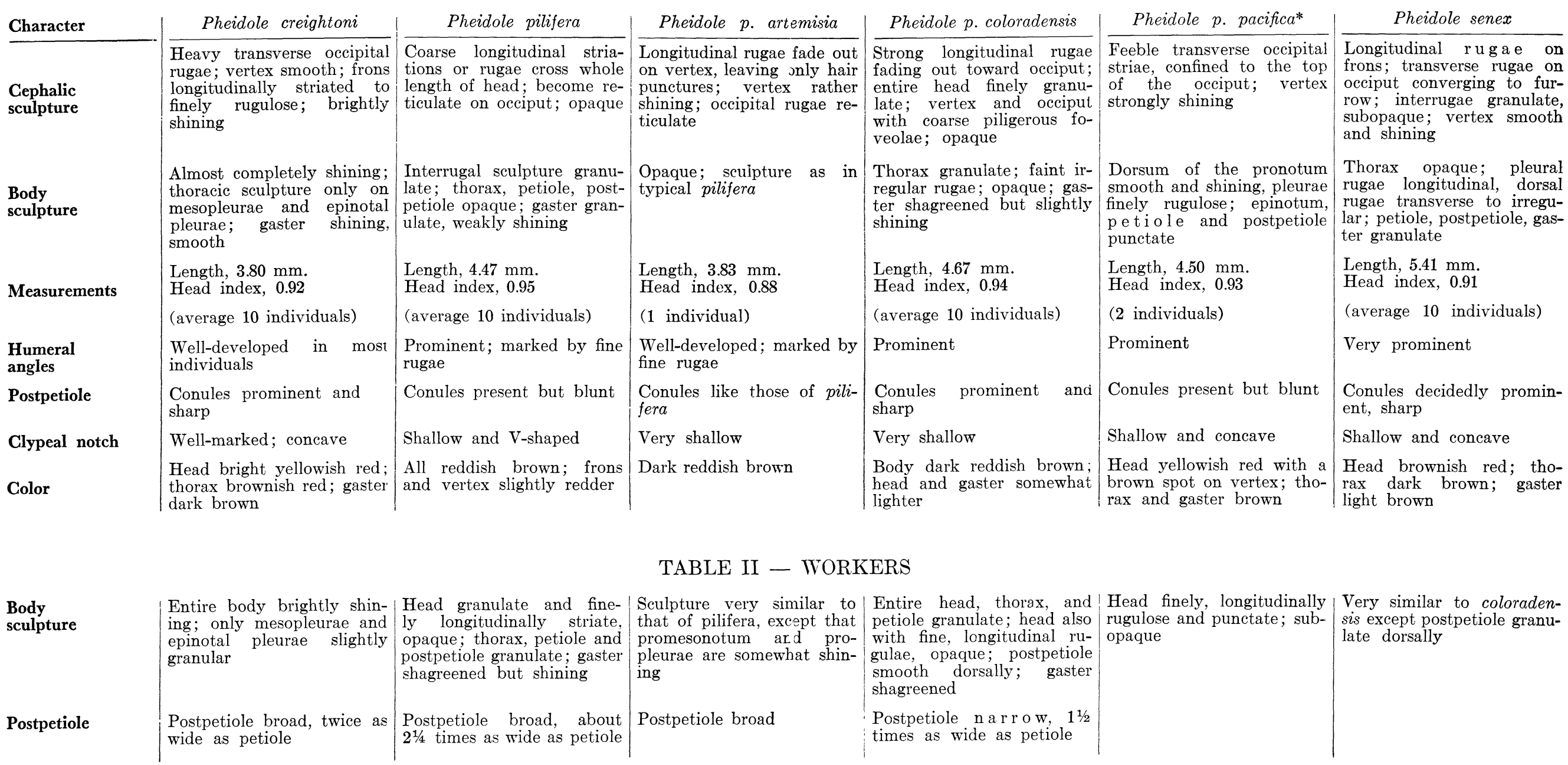

* Specimens not seen. The species is known only from types in the American Museum of

Natural History, the Museum of Comparative Zoology, and the collection of W. S.

Creighton. Data were obtained from the literature and from Dr. Creighton. 
spines short and triangular, but sharp. Scapes reach to the occipital corners of the head. Gaster glabrous and shining. Color of entire body dark brown, legs and antennae light brown.

Female: Length, $5.25 \mathrm{~mm}$.; head index, 1.0; head length, $1.10 \mathrm{~mm}$.; thorax length, $1.58 \mathrm{~mm}$.

Resembles soldier in most respects, but differs from that caste in the following ways. Body size larger, head quadrate, frontal area level with the general surface of the head (not depressed), compound eyes large and occupying a proportionately greater area on the sides of the head, vertex with three prominent ocelli, occipital lobes are not as pronounced and the furrow is shallower, scapes reach approximately half way from their insertions to the corners of the lobes, and the mandibular teeth are sharper and more distinct. Entire dorsal and lateral surfaces of the head covered with rugae which are longitudinal on the frons and genae, but curve to parallel the occipital lobes, bend centrally and become transverse on the occiput and in the furrow. Interrugal sculpture consists of fine striae, granules, and large dimples or foveae. Surface shining despite the sculpture but less so than in the soldier.

Thorax flat except where mesonotum descends abruptly to the pronotum; dorsum of pronotum, mesonotum, and metanotum shining and smooth except for piligerous punctures; propleurae and epinotal pleurae with parallel rugulose sculpture, subopaque; epinotal base rugulose, declivity smooth; epinotal spines short, conical, and half as long as their interbasal distance. Petiole and postpetiole like those of the soldier, opaque; lateral conules of the postpetiole very prominent and bluntly rounded at the tips. Gaster sharply truncate at the base, anterior margin straight. Wings transparent, stigma pale brown, one discal cell. Head and mandibles reddish brown, thorax darker, gaster dark brown, legs and antennae light brown.

Male: Length, $4.08 \mathrm{~mm}$.; head index, 1.14; head length, $0.58 \mathrm{~mm}$.; thorax length, $1.58 \mathrm{~mm}$.

Explanation of Plate 3

Pheidole creightoni, a female (deälate); b. male; c. head of male. All figures are drawn to the same scale. 

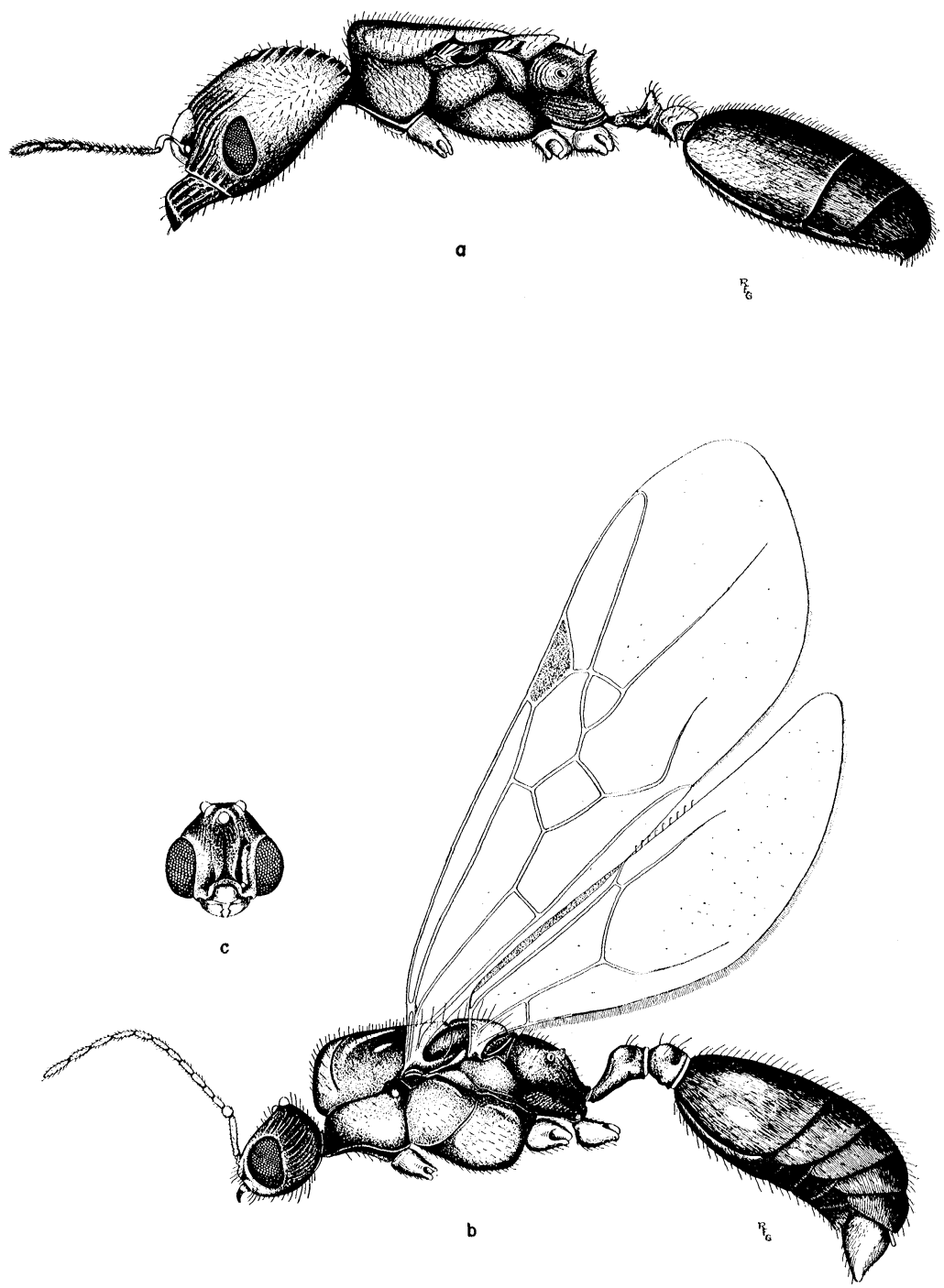

Gregg - Pheidole creightoni 
Head wider than long, obovate, anterior end broader. Compound eyes large and occupying fully half the sides of the head; three ocelli situated on prominent elevations of the vertex which cause the head to appear produced dorsally. Clypeus convex, anterior border entire. Mandibles small, narrow, with one apical tooth and two minute denticles. Frontal area broadly triangular. Antennae 13segmented; scape short, equal to the combined length of the first two funicular segments; first funicular segment globular.

Thorax almost 11/2 times as wide as the head. Mesonotum flat dorsally, scutellum convex; Mayrian furrows present except for the medial stem which is almost obsolete; parapsidal furrows or sutures absent; epinotum descends rapidly to the petiolar junction, epinotal spines absent. Petiolar node low and rounded, except for slight superior angles. Postpetiole broad and subquadrate, lateral conules very short and blunt. Gaster of the usual elliptical shape. Stipites convex, curved medially and bulbous at the apex; cerci minute and cylindrical.

Head coriaceous, sculpture consisting of fine striations and granules, subopaque. Thorax shining except for fine striae on the anterior vertical border of the mesonotum; entire metathorax and propodium finely granular, opaque. Petiole, postpetiole and gaster smooth and shining. Fine, pointed hairs cover all surfaces of the body and appendages except the scapes and funiculi. Head black, mandibles and antennae yellow, thorax, abdomen and legs brown. Wings transparent, stigma pale brown, one discal cell.

Holotype: soldier, located in the author's collection.

Paratypes: 219 soldiers, 379 workers, 4 females, and 40 males, deposited in the author's collection, and the collections of W. S. Creighton, the American Museum of Natural History, the Museum of Comparative Zoology, and the United States National Museum.

Type locality: Three miles east of Applegate, Oregon; elevation 1500 feet. This town is about 20 miles west of Medford, on the northern slope of the Siskiyou Mountains, in southwestern Oregon.

Material examined: The specimens upon which this 
species is based represent nine separate colonies collected on July 24, August 12, August 16, September 18, and September 22, 1952. They were all secured by Dr. and Mrs. Creighton from the same place (type locality), and winged castes were present in the colonies obtained on August 12, September 18 and 22. ${ }^{1}$

Variation in type material: About one-third of the soldiers have the vertex very smooth and absolutely devoid of sculpture save for minute piligerous punctures, the remainder showing exceedingly fine striations confluent with the rugae on other parts of the head. This delicate sculpture, however, does not reduce the brilliant surface of the vertex in the specimens to hand. Soldier mandibles may have the two apical teeth absent or nearly so, and give the appearance of having been worn down by long continued use. One soldier showed vestiges of the two lateral ocelli, and one colony contained 15 soldiers in which the postpetiolar conules were so reduced as to be nearly absent. Worker scapes just reach the occipital corners or very slightly surpass them. There are elusive differences in color among the many specimens seen, some being slightly darker in over-all tone, but these fluctuations are regarded as inconsequential.

Affinities: This ant is closely related to members of the pilifera complex, and in fact runs out to this group in Creighton's recent key (1950), but fails to fit any of the forms treated. Perusal of the accompanying tables (Table I and Table II) will help to distinguish the new ant, creightoni, from its relatives for the important diagnostic features have been emphasized, especially of the soldier caste. Of these, it has been found that the most valuable characteristics for separating creightoni from other forms of the pilifera group are, (1) its small size (except for artemisia), (2) the nature and distribution of particularly

${ }^{1}$ Since this paper was submitted, Dr. A. C. Cole very kindly sent me a sample of $P h$. creightoni containing four soldiers and numerous workers which he collected at Winnemucca, Nevada, elevation 4334 feet, on July 8, 1954 (Cole Collection \# 212). The specimens appear in every way to be conspecific with the types of the new species, and this opinion has been confirmed both by Dr. Cole and by Dr. M. R. Smith. 
the cephalic sculpture, together with the weakness of the interrugal sculpture which leaves the whole surface very shining, (3) the clypeal notch which is very well-developed, and (4) the color which is yellowish red in large part as compared to the reddish brown to brown color of the other species.

Dr. Creighton has also supplied pertinent field notes concerning the new species which give interesting information about the biology of this ant. The nests are populous and are surrounded by large amounts of chaff. Both workers and majors forage for food and move in files. The ants are not only granivorous but carnivorous as well, for the blood and tissues of purposely shot ground squirrels, placed nearby, were accepted as food. About eighteen colonies were seen altogether, and it is said that the nests are frequently excavated near those of Veromessor andrei. Males and females of creightoni emerge in small numbers (approximately two dozen) each day about one hour before sunset. The worker ants remain in the nest most of the day, but they become active in the late afternoon before the flight takes place. The marriage flights which were observed lasted from September 15 to September 21.

\section{Literature Cited}

Creighton, W. S.

1950. The ants of North America. Bull. Mus. Comp. Zool., 104: 163. 

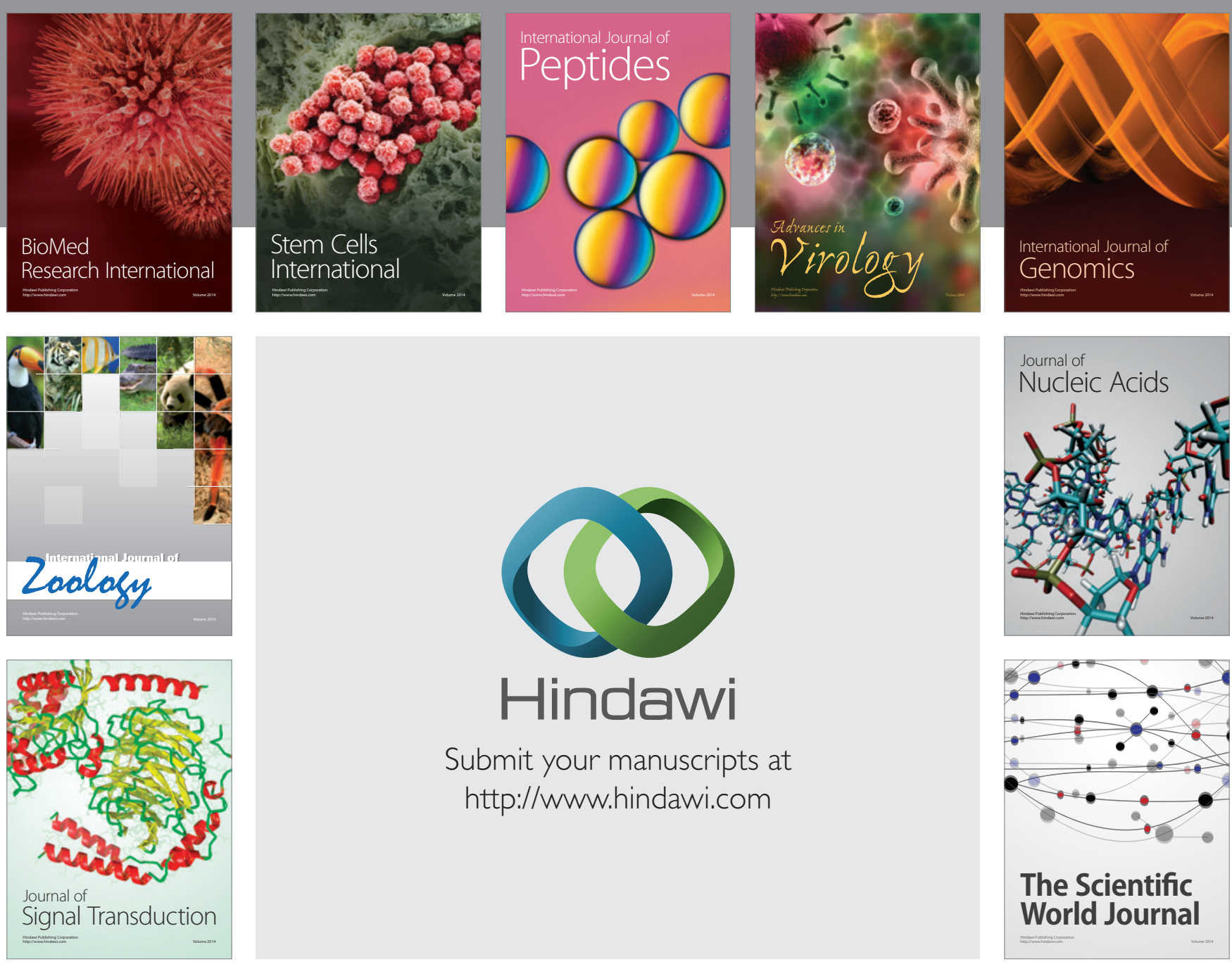

Submit your manuscripts at

http://www.hindawi.com
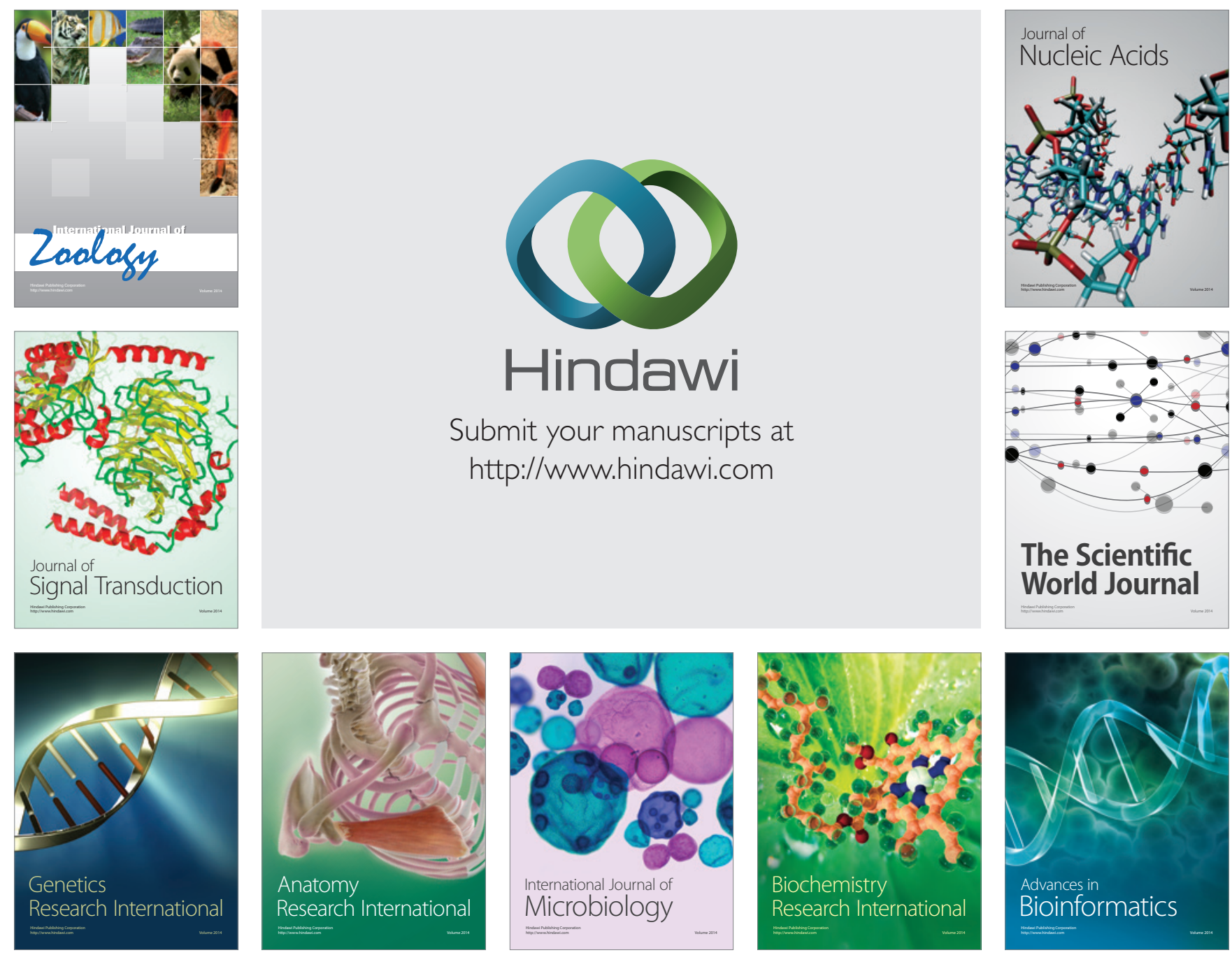

The Scientific World Journal
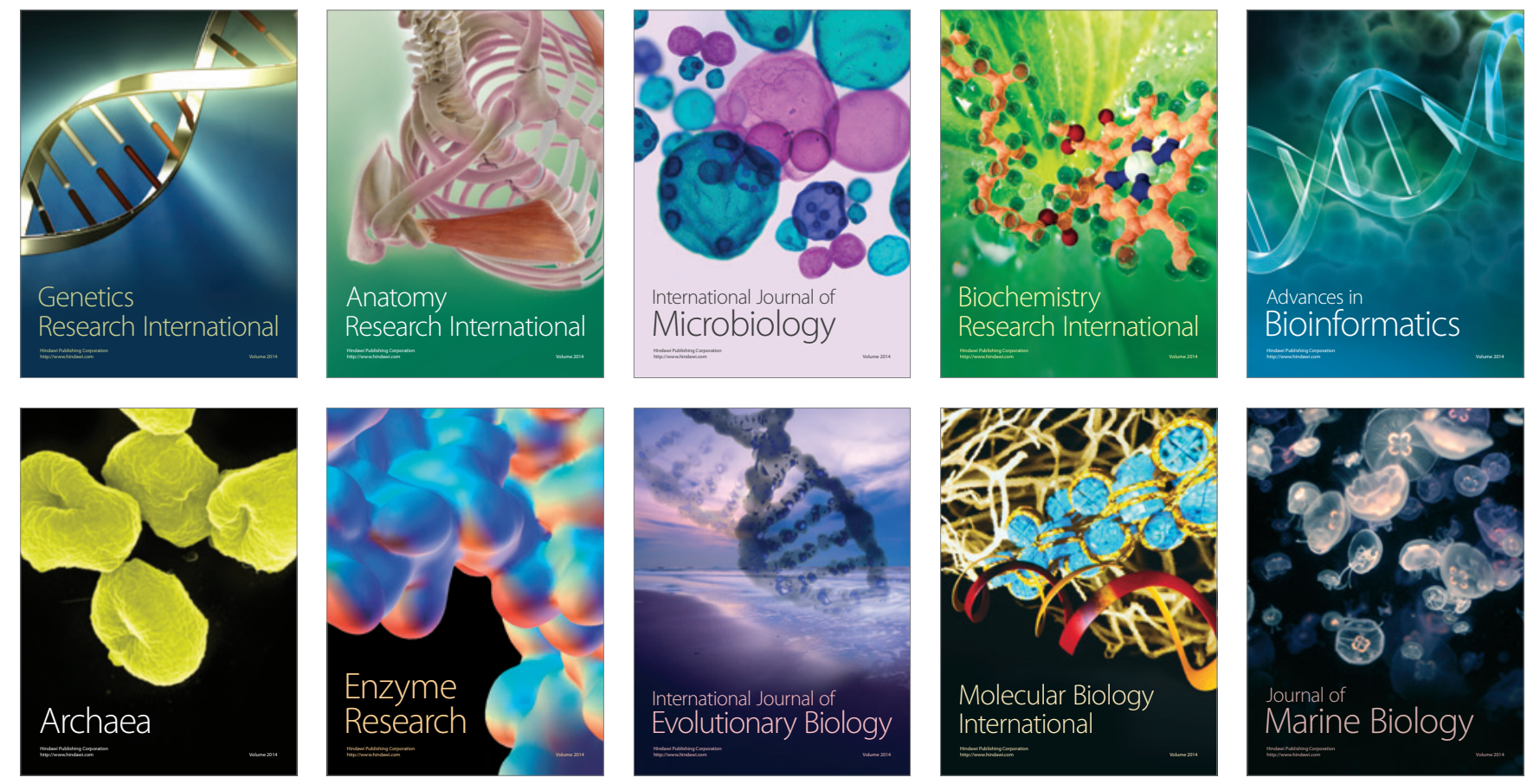